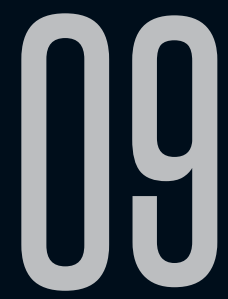

\title{
LO MONSTRUOSO NEOFANTÁSTICO DE SACRILEGIO: LA MONSTRUOSIDAD EN LOS UMBRALES
}

Nini Johanna Sánchez Ávila (FUAC)

Recebido em 29 dez 2019. Nini Johanna Sánchez Ávila es Candidata a Doctora Aprovado em 28 mar 2019. en Artes, Universidad de Antioquia (Colombia). Profesora de Literatura en la Universidad Distrital Francisco José de Caldas (UDFJC) y la Universidad Autónoma de Colombia (FUAC). Docente de pedagogía de la literatura, teoría literaria, además de literatura y artes en pregrado y maestría. Ha publicado artículos sobre literatura fantástica colombiana como: "Desdoblamiento como eje composicional en los cuentos de Germán Espinosa" (Revista La Palabra) y "Reinterpretación de los sujetos de poder en Los cortejos del diablo: lectura de la modernidad en Colombia" (Revista Pretil). Investigadora de literatura fantástica y la relación entre literatura y artes, perteneciente al grupo LEC (Literatura, Educación y Comunicación) de la UDFJC; ha desarrollado recientemente los proyectos: "Manifestaciones y representaciones del ser: transformaciones, desdoblamientos y rupturas en la obra cuentística de Germán Espinosa" (2016); "Configuración de una teoría articulada de la Literatura Fantástica como contribución a las posibilidades de desarrollo del género" (2017) y "El área de literatura de la Licenciatura en Educación Artística: sistematización de experiencias en torno a los procesos de enseñanza y aprendizaje (2018). 
Resumen: La novela Sacrilegio, escrita en el año 2009, forma parte de la nueva producción de literatura fantástica que se produce en Colombia. Se trata de una narrativa que dialoga con diferentes tradiciones pues recupera elementos del folklore sobrenatural para enlazarlo con nuevas formas de representación en las que prima lo neofantástico y las nuevas monstruosidades. Así mismo, parte de esta nueva narrativa fantástica plantea, también, la negociación entre géneros pues ya no se desarrolla solamente un relato centrado en un tipo de horror o en una sola ruptura de la realidad, sino que busca la confluencia de formas de lo fantástico. Por ello, Sacrilegio vincula la distopía, el horror (tanto psicológico como cósmico) y elementos del folklore sobrenatural propios de la Amazonía Colombiana. El texto busca analizar la novela desde la propuesta de lo neofantástico y las nuevas formas de monstruosidad, para destacar: los procesos de creación de nuevos seres, la diseminación de voces narrativas, la hibridación corporal y espacial, y así observar la confrontación de subjetividades y de identidad. Esta convergencia de visiones sobre lo fantástico requiere un acercamiento a la obra desde autores como Jaime Alazraki (2001) y David Roas (2000 y 2001) quienes plantean nuevas perspectivas del género. Igualmente, se presenta un acercamiento a las nuevas rupturas del sujeto a partir de la construcción de una monstruosidad de umbral, incluso proteica, que dialoga con las nuevas formas de lo fantástico. Para esta última parte se hará relación a las propuestas de David Roas (2013), Hector Santiesteban (2003), Lucian Boia (1995) y William Turner (1988), quienes abordan desde perspectivas diferentes la evolución de la otredad y con ello, la evolución de la monstruosidad. Palabras clave: Monstruosidad; Neofantástico, Umbral; Distopía.

Resumo: O romance Sacrilégio, escrito em 2009, faz parte da nova produção de literatura fantástica produzida na Colômbia. É uma narrativa que dialoga 
com diferentes tradições porque recupera elementos do folclore sobrenatural para ligá-la a novas formas de representação nas quais prevalecem as neofantásticas e novas monstruosidades. Além disso, esta fantástica evidência uma nova negociação narrativa entre gêneros, porque já não se desenvolve apenas uma história centrada em um tipo de horror ou uma única pausa da realidade, mas procura a confluência das formas fantásticas. Portanto, Sacrilegio liga a distopia, o horror (tanto psicológico quanto cósmico) e elementos do folclore sobrenatural típico da Amazônia colombiana. O texto procura analisar o romance abordando a proposta do neo-fantasticoé e das novas formas de monstruosidade, para destacar: os processos de criação de novos seres, a disseminação de vozes narrativas, a hibridização corporal e espacial, e assim observar o confronto de subjetividades e identidade. Essa convergência de visões sobre o fantástico requer uma abordagem do trabalho de autores como Jaime Alazraki (2001) e David Roas (2000 e 2001) que levantam novas perspectivas do gênero. Da mesma forma, uma abordagem às novas rupturas do sujeito é apresentada a partir da construção de uma monstruosidade liminar, até mesmo protéica, que dialoga com as novas formas do fantástico. Para esta última parte será sobre as propostas de David Roas (2013), Hector Santiesteban (2003), Lucian Boia (1995) e William Turner (1988), que abordam de diferentes perspectivas a evolução da alteridade e, com ela, a evolução da monstruosidade.

Palavras-chave: Monstruosidade; Neo-fantástico, Limiar; Distopia.

\section{PRESENTACIÓN DE LA OBRA}

Sacrilegio es una novela colombiana escrita en el año 2009 por Simón Jánicas -seudónimo que mantiene al autor en el anonimatoy es editada por Diente de León. Sacrilegio desarrolla un relato que 
oscila entre lo distópico y el horror sobrenatural: se trata de una novela que nos ubica a finales del siglo $X X$ y comienzos del siglo XXI en un momento de cambio histórico que da lugar a una guerra santa que transformará el panorama de la humanidad y generará una nueva historia y una visión distópica del mundo en el año 2335.

\section{SIMÓN JÁNICAs}

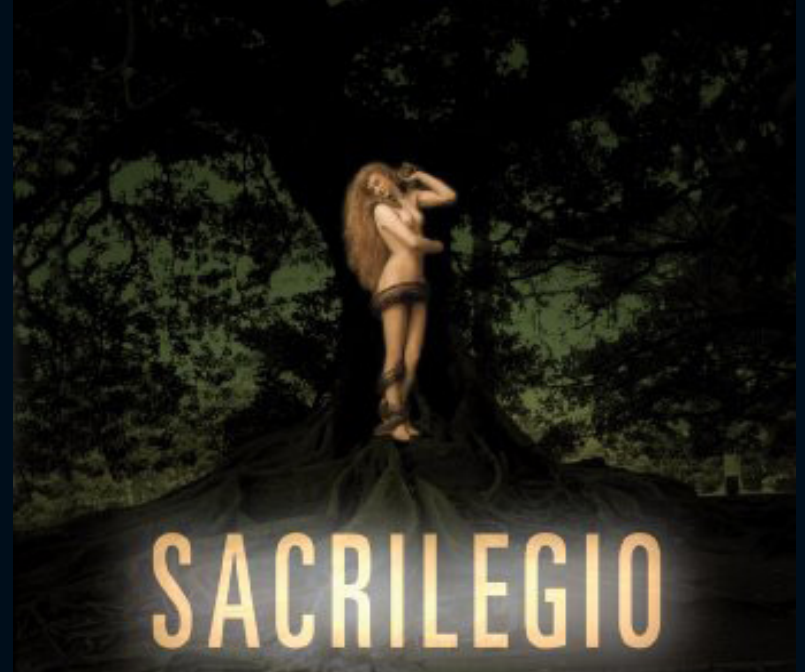

\section{HOVELA}

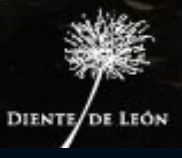

Figura 1: Imagen de sobrecubierta Sacrilegio ${ }^{1}$

1 Imagen de sobrecubierta de la novela Sacrilegio (2009), tomada de la página de la Editorial Diente de León. In https://www.dientedeleon.com.co/titulos-publicados acceso en 1.Dic.2018. 
El relato gira en torno a los indígenas Iseieke que son descritos como sabios que trascienden el concepto de unidad del sujeto para hacerlo múltiple a través de los siglos y buscan llevar a la raza humana a nuevo orden mundial. En la novela tanto el concepto de sujeto como el de ambiente se transforman constantemente construyendo dobles, avatares y fusiones (se mezclan diferentes naturalezas humanas, animales y vegetales); además, aparece una Cosmópolis monstruosa denominada Ayrebarke, una ciudad abismal donde todos los caminos y los mundos convergen en todos los tiempos y realidades posibles, un espacio de oscuridad profunda que se muestra en tonos de negro y es sólo visible a los iniciados en sus secretos:

Desde el orbe de los sueños, Mi voz le susurraba un cántico sibilino, placentero y desgarrador, desde cuyo sonido comenzaban a brotar las sombras de una imagen infinita. Yo le decía que por uno de los arcanos del Caos ella podría entrar en el Multiverso de los sueños. (JÁNICAS, 2009, p. 15)

Así, la ciudad y la selva convergen como catalizadores de la muerte y la vida que emana la una de la otra. También se reconoce que la ciudad no es un lugar en el sentido convencional, sino que es una experiencia: aparece a partir de un llamado que hace el dios oscuro que la rige y se va materializando de adentro de los sujetos afuera, lo que quiere decir que la ciudad es un espacio interior que aflora como un encantamiento, del poder de la palabra.

Convergen entonces en la novela espacios que se transforman y se rompen: espacios urbanos y selváticos, espacios corporales, además de espacios oníricos que se mezclan. Igualmente, la representación de los sujetos se fragmenta y aparecen imágenes 
de lo humano diferente, de lo monstruoso múltiple; es en esta confluencia de espacios y sujetos que se plantea un análisis para abordar las formas de monstruosidad latentes en el relato y que pueden llevar a reconocer una estética neofantástica.

\section{APROXIMACIÓN A LO NEOFANTÁSTICO Y LAS NUEVAS CARAS DEL MONSTRUO}

La literatura fantástica contemporánea establece lazos con la sensibilidad posmoderna. A partir de este acercamiento aparece la visión de un mundo desestabilizado: sin modelos de realidad o tradiciones de pensamiento que puedan explicar y articular la conciencia humana; sin signos privilegiados con legitimidad definitiva; sin posibilidad de totalizar o de racionalizar la experiencia.

Ante esta acumulación de imposibilidades, autores como Jaime Alazraki y David Roas plantean: "si no sabemos qué cosa es la realidad, ¿cómo podemos plantearnos transgredirla? Más aún, si no hay una visión unívoca de la realidad, todo es posible, con lo cual tampoco hay posibilidad de transgresión." (ROAS, 2000, p.59). Alazraki desarrollaría su concepto de nuevas formas de lo fantástico (neofantástico) planteando que aunque la realidad sea una apariencia o un simulacro, se trata de uno que ha sido aceptado colectivamente como representación de lo posible y de lo normal; así, lo neofantástico aparece como una ruptura de lo normal aceptado, una trasgresión de los estándares de realidad, aunque estos sean inestables, huidizos y se trate de metarrelatos -como organizadores de nuestras visiones de mundo- que van perdiendo vigencia (LYOTARD, 1987). Por ello, Alazraki plantea lo neofantástico desde tres ejes: 
a) "lo neofantástico asume lo real como una máscara" (ALAZRAKI, 2001, p.276) entonces habría una realidad diferente, una realidad otra (o múltiples realidades) que esconde la verdadera naturaleza del mundo.

b) La intención narrativa de lo neofantástico no está en el miedo o en la vacilación clásicas, sino en "metáforas que buscan expresar atisbos, entrevisiones o intersticios de sinrazón que escapan o se resisten al lenguaje de la comunicación, que no caben en las celdillas construidas por la razón" (ALAZRAKI, 2001, p.177), de ahí que se trate de imágenes que tratan de dar acceso a lo indescifrable, materializar lo indecible que no entra en las nociones racionales de la construcción de realidad aceptada.

c) El relato neofantástico abandona la ruptura gradual de lo real, es decir, no presenta lo real para romperlo paulatinamente, sino que desde el comienzo de la narración se presenta la grieta, lo anormal aparece desde el comienzo.

Así, la propuesta de lo neofantástico busca expresar la complejidad de una realidad multidimensional y multitemporal. Deconstruye los metarrelatos de realidad para reconstruir una visión del mundo que permita reconocer el caos en el universo circundante.

De manera complementaria a esta nueva mirada de lo fantástico, David Roas nos da un esbozo de lo que serán las nuevas monstruosidades. En su presentación al número monográfico sobre el Monstruo Posmoderno y nuevas estrategias de la ficción fantástica de la Revista de Estudios Hispánicos Pasavento (2013), Roas ubica al monstruo como parte de la estructura de lo fantástico: 
"el monstruo encarna en sí mismo esa dimensión transgresora: no solo sirve, como decía, para representar (y provocar) nuestros miedos, sino también como vía para problematizar nuestros códigos cognitivos y hermenéuticos." (ROAS, 2013, p.8), de esta manera el monstruo fantástico se convierte es una estrategia para subvertir la noción de realidad y de normalidad.

Entonces, si la concepción de realidad va cambiando y se va haciendo compleja (ya sea que se diluya, se deconstruya o se haga múltiple) la noción del monstruo debe cambiar también en correspondencia. Por lo que pueden producirse dos desarrollos, según Roas:

a) Aparecen obras que "banalizan y/o domestican al monstruo, despojándolo de su excepcionalidad" (ROAS, 2013, p.8), es decir que el monstruo termina siendo incorporado a la estructura de lo real y ya no rompe la norma, por lo que su originalidad, su diferencia se disipa.

b) Aparecen nuevas formas para potenciar sus rasgos esenciales, siendo el determinante la imposibilidad. Además, en esta segunda línea de desarrollo el monstruo tiene otro aspecto destacable: se le da voz directamente, por lo que se hace narrador de su propia historia. Finalmente, esta tendencia puede recurrir a la ironía y a la parodia como elemento que renueva y potencia la monstruosidad.

La novela Sacrilegio juega con este tipo de nuevas representaciones al mostrar varias formas de representación de la realidad que convergen en la historia: una mirada concierne al abismo entre clases sociales, los dominantes políticos y económicos versus 
los dominados; pero también muestra las mismas comunidades marcadas por la ortodoxia religiosa y la heterodoxia; no se centra en una sola comunidad religiosa, sino que plantea a los ortodoxos y heterodoxos de cualquier posible secta y religión. La polaridad, entonces, vista como una abominable monstruosidad del ser, se convierte en el discurso a combatir. Sería esta la indecible naturaleza de lo humano que va aflorando para destruir al mundo, mientras que los tradicionales comportamientos monstruosos adoptan aquí la categoría de deber ser: todos los sujetos deberían abrazar su profunda multiplicidad y en ella convertirse en verdaderamente humanos, en radicalmente diferentes.

\section{¿CÓMO SE PRODUCEN LOS SERES MONSTRUOSOS?}

Para contextualizar la forma en que emergen los monstruos y cómo se llegará a una propuesta de monstruosidad neofantástica, se retoma el trabajo de Lucian Boia (1995) Entre el ángel y la bestia: el mito del hombre diferente desde la antigüedad hasta nuestros días. Para Boia hay una obsesión en todas las culturas, desde la antigüedad, con la diferencia, el misterio de la alteridad radical. Por ello:

Para asir al personaje de mil rostros, a veces incluso sin rostro, estamos obligados a desplazarnos hacia los confines del perímetro humano y más allá, y penetrar en una zona de contornos imprecisos en que se transgreden constantemente las normas generalmente admitidas de la condición humana. (BOIA, 1995, p.12)

El otro, ese ser enigmático, monstruoso y aterrador, permite que el hombre se reinvente asumiendo multiplicidad de caras, 
de vidas y experiencias que normalmente están prohibidas por el status quo. Es un fantasma de lo humano que juega con semejanzas y diferencias para amplificar los rasgos de anormalidad (biológica, psicológica y cultural). De ahí que los hombres diferentes puedan reconocerse ligados a tres dimensiones que organizan sus rasgos monstruosos:

a) La acción sobre el cuerpo. En este nivel los hombres se hacen diferentes debido a la manipulación del cuerpo como frontera que delimita lo normal: aparecen alteraciones de las dimensiones; juegos de deformidad, diseminación, hipertrofia (falta o exceso); e hibridación entre lo humano, lo vegetal, lo animal y metafísico (unión con los dioses, longevidad por espiritualización). También se encuentra el imaginario de la mutación a partir de la ciencia y la tecnología,

b) El espíritu diferente. Esta dimensión refiere a la diferencia que late en lo humano a partir de grados de conciencia e inteligencia, el grado de comprensión que se tenga del mundo o la perspectiva de interpretación que se tenga (racional, religiosa, irracional, onírica). Cada grado de conocimiento se manifiesta en asociación con un grado de corporalidad, es decir, tanto los rasgos que se consideren positivos, como los defectos se materializan en una configuración del cuerpo (síntesis simbólica de la interioridad como la apariencia angelical, la fealdad extrema, la putrefacción o la ceguera).

c) Las costumbres y el comportamiento. Finalmente, este último aspecto plantea que la condición humana se establece a través de la reglamentación social dada en límites, premisos 
y tabúes. Así, los ámbitos más importantes y recurrentes entre culturas estarán asociados a la comida (canibalismo, vegetarianismo, alimento crudo); y a la sexualidad (desnudez, incesto, promiscuidad, homosexualidad). Aunque las normas se extiendan a otros ámbitos del comportamiento.

En este marco, el monstruo neofantástico retoma los niveles de transgresión generales, pero no los repite de manera tradicional, sino que juega a establecer momentos de normalidad en los cuales puede simular, en un plano o en una estructura de realidad, para desmantelarse en otras. De ahí que se constituya como sujeto de alteridad extrema, de movilidad y de ambigüedad.

\section{LA VOZ DISEMINADA DEL MONSTRUO EN SACRILEGIO}

La monstruosidad adopta formas imprevistas en la novela Sacrilegio (2009) empezando por la eliminación del autor que se desdibuja a través de su seudónimo que es casi un heterónimo. Aún no sabemos quién está detrás de Simón Jánicas, pero al consultar sobre el autor aparece una breve biografía en su perfil de Blogger:

Él afirma haber nacido en algún lugar de la Latinoamérica profunda en la segunda mitad del siglo XX. Vivió entre las sombras, las luces, los sonidos y los olores de las selvas y las montañas donde no se conocen las fronteras trazadas por el hombre. Sin embargo, en la actualidad, es un peatón anónimo en las grandes urbes del mundo donde se solaza y sufre con la cultura global. (JÁNICAS, 2009b, p.1)

Habla de sí mismo describiéndose en tercera persona. Los editores mantienen el secreto de su identidad e incluso en la solapa del texto afirman que el texto llega a través de un abogado que 
se presenta como apoderado del escritor y que todo contacto se reduce al anonimato de unas cuantas llamadas y ninguna presencialidad. En el mismo Blog del escritor aparece también una "supuesta" entrevista concedida a un analista literario apellidado Correa-Fajardo (otro personaje ficcional) que es invitado por el autor para hablar de la novela y que éste pueda hacer una reseña del libro y el autor. El relato se convierte en una expansión de la obra que pretende ubicar al analista en una trama conspiratoria en la que incluso aparece uno de los personajes de la historia. Así, el autor queda escondido a través de su avatar y se convierte en una fantasma del autor, un juego de lenguaje.

Ya en el texto de la novela nos encontramos con dos estrategias importantes para determinar las formas narrativas que adopta la monstruosidad: la primera tiene que ver con el narrador que aparece desde el comienzo como un narrador omnisciente que evalúa acciones y personajes conociendo tanto lo que hacen como lo que piensan, sin embargo, casi de inmediato pasa a ser un narrador intradiegético: "Mi voz irrumpió en su conciencia desde la oscuridad infinita" (JÁNICAS, 2009a, p.11); "Mi voz le susurraba" (2009a, p.15); "Destejo Mis nudos para salir y enquistarme poco a poco en el interior de cualquier cuerpo humano" (2009a,p.17); el transcurso de la narración plantea una incesante oscilación entre la voz en primera persona de los personajes, el narrador externo pero omnisciente $y$ este narrador en primera persona que va colonizando el discurso para hacer de todas las historias su única historia. Él es todos, él es cada uno de los personajes (principales y secundarios), como si fuese un registro de su conciencia y de la memoria humana. 
A su vez, los personajes van pasando por distintos momentos de transformación. Se trata de un cambio que va operando de dos maneras: los personajes recuerdan vidas pasadas, experiencias vividas y sus muertes anteriores, pero entienden que su historia es única y continua y que cada vida contribuye a la misión de una deidad aterradora que habita en el centro del mundo, en el centro de la Amazonía, así como en el centro de cada ser humano. Se trata de:

La Tarasca, La Serpiente, El Dragón o La Bestia. Pero la palabra Ofiuco es la que más Me satisface porque designa a quién subyuga la potencia cismática de todas las proliferaciones del gran ofidio subterráneo. En fin, soy un Superorganismo de nudos. (JÁNICAS, 2009 a, p.17 el resaltado es nuestro).

Esta figura de una deidad oscura, multiforme y omnipresente se va a representar con dos serpientes que se autodevoran, imagen que se sugiere en los nombres que recibe. Partiendo de esta representación simbólica se desarrolla todo un esquema de duplicidad que marca, no solo a la deidad amazónica y ancestral, sino a los personajes tocados por su oscuridad. Esta constante transformación de los sujetos se evidencia en el siguiente cuadro: 


\section{TRANSFORMACIÓN Y ASOCIACIÓN DE LOS PERSONAJES (DUPLICIDAD2)}

\begin{tabular}{|c|c|c|c|}
\hline 1999 & $\begin{array}{l}2335 \text { (después } \\
\text { de } 336 \text { años de } \\
\text { guerra santa) }\end{array}$ & Antigua China & Tribu de los Iseieke \\
\hline $\begin{array}{l}\text { Emmanuelle Bazin } \\
\text { (Diseñadora y } \\
\text { modelo francesa) } \\
\text { Conspiradora } \\
\text { y sacerdotisa } \\
\text { vestal (encargada } \\
\text { de esparcir la } \\
\text { oscuridad) }\end{array}$ & $\begin{array}{l}\text { Niño salvaje- } \\
\text { mutante } \\
\text { Astronauta- } \\
\text { cazador }\end{array}$ & $\begin{array}{l}\text { Zan (infiltrado } \\
\text { en la corte de } \\
\text { Chow Sin, papel } \\
\text { de corruptor y } \\
\text { verdugo) }\end{array}$ & $\begin{array}{l}\text { Atemporales } \\
\text { Mutantes }\end{array}$ \\
\hline $\begin{array}{l}\text { José Asunción } \\
\text { Toscano (obispo } \\
\text { católico de } \\
\text { Leticia, Amazonía } \\
\text { Colombiana) } \\
\text { Daniela Sarmiento } \\
\text { (emisaria de los } \\
\text { Iseieke) } \\
\text { Étienne Millet } \\
\text { (fotógrafo y } \\
\text { acompañante de } \\
\text { Emmanuelle) }\end{array}$ & $\begin{array}{l}\text { Heraldo Serpiente } \\
\text { y Heresiarca de la } \\
\text { Amazonía }\end{array}$ & & $\begin{array}{l}\text { Ciudad de } \\
\text { Ayrebarke } \\
\text { Necrópolis } \\
\text { Amazonía } \\
\text { Corazón del mundo } \\
\text { y del sujeto }\end{array}$ \\
\hline $\begin{array}{l}\text { Hermanos Grimm } \\
\text { Richard (Hermano } \\
\text { mayor) - vinculado } \\
\text { con la aristocracia } \\
\text { neoconservadora } \\
\text { en USA } \\
\text { Arnold (Hermano } \\
\text { menor) - liberalismo } \\
\text { político (JFK) - líder } \\
\text { inmolado }\end{array}$ & & $\begin{array}{l}\text { Chow Sin (Tirano) } \\
\text { Opositor y } \\
\text { corrupto } \\
\text { Wen (Principe } \\
\text { justo - budista) } \\
\text { Inmolado }\end{array}$ & $\begin{array}{l}\text { Ofiuco (dios oscuro } \\
\text { y narrador de la } \\
\text { novela) } \\
\text { Asclepio - vencedor } \\
\text { de la muerte } \\
\text { Cronos - devorador }\end{array}$ \\
\hline
\end{tabular}

Tabla 1. Elaboración propia

2 Acá se alude a tres formas de desdoblamiento como rupturas del sujeto en la literatura fantástica: la fusión (unión de dos para conformar un sujeto); la fisión (separación de dos entidades de un sujeto original) y metamorfosis (como transformación que puede ser asociada tanto al cambio corporal reversible, como al no reversible y puede aludir también a la metempsicosis o reencarnación). El tema se desarrolla completamente en el artículo de Nini Johanna Sánchez "Desdoblamiento como eje composicional en los cuentos de Germán Espinosa" que se incluye en las referencias. 
El cuadro describe y vincula la forma en que los personajes se relacionan a través de los tres relatos que se desarrollan en la novela: el primero empieza en 1999, año que marca el descubrimiento de la tribu indígena y en el cual empieza un proceso de despertar de los sujetos para cumplir con la misión revolucionaria y conspiratoria dada por el dios Ofiuco. El segundo momento está en un pasado remoto en el cual se remite a la antigua china (sin referencia exacta de año, ni mención a personajes históricos rastreables), temporalidad que le ayuda a los personajes de 1999 a recordar su antigua misión, siempre presente en todas sus encarnaciones. Cada vez que se ejecuta el plan maestro para desestabilizar el poder hegemónico aparece una triada de personajes que deben cumplir los mismos roles: unos dominar, otros se transforman en mesías del cambio y otros, en el medio, traman una traición que posibilite la transformación social.

La tercera y última temporalidad aludida se da en un futuro remoto en el cual el dogmatismo, el absolutismo ideológico y el capitalismo extremo como única creencia humana han tomado el poder y han devastado a la humanidad-física y espiritualmente-. En el año 2335, las consecuencias de la guerra santa contra los herejes mutantes (aquellos que despertaron con una conciencia nueva de multiplicidad en el año 1999) han provocado que la humanidad esté al borde de la extinción y que los sujetos convivan en dos extremos: gobernantes marcados por una alta tecnificación social y sujetos subyugados que han involucionado hasta hacerse salvajes (tratados como animales, sin capacidad de comunicarse por lenguaje verbal y a merced de la cacería constante de los astronautas cazadores). Los relatos en las tres temporalidades se van intercalando para unirse 
al final del relato en un mismo futuro desolador y apocalíptico, haciendo de la narración una experiencia fragmentada, monstruosa en sí misma. Además, personajes que en la primera temporalidad aparecen como tres personas diferentes (José Asunción Toscano, Daniela Sarmiento y Étienne Millet) se fusionan en el siguiente relato para convertirse en un sujeto que los incorpora (El heraldo serpiente); otros cambian de sujetos femeninos (Emmanuelle Bazin) a sujetos masculinos (Zan) en otras líneas temporales. Pero, al final, todos van a hacer parte tanto del Ofiuco como de la ciudad mítica de Ayrebarke.

El último elemento que mencionaremos sobre la voz del monstruo multiforme está dado por la lengua que habla el pueblo indígena de los Iseieke, tribu que hace parte del cuerpo y el espíritu de la deidad oscura. Su lenguaje está hecho por sonidos ininteligibles que no corresponden a ninguna lengua natural y en la cual solamente se distinguen fonéticamente dos palabras: la del nombre de la tribu y la de la ciudad legendaria de Ayrebarke, siendo la tribu, la ciudad y la deidad una sola creatura viviente y gimiente. En el texto se describe como la lengua original de Babel, imposible de aprender y pronunciar pero que puede ser entendida por cualquier hablante del planeta pues late en lo hondo de todas las conciencias.

\section{HIBRIDACIÓN DEL CUERPO Y EL ESPACIO EN LA MONSTRUOSIDAD}

Como se alcanza a entrever del apartado anterior, Ayrebarke más que una ciudad es un multiverso, una ciudad de ciudades y al tiempo, una necrópolis subterránea. Es un espacio hecho de 
obsidiana con espejos de oscuridad donde todo se ve en tonalidades de penumbra y profundidad. La oscuridad de la ciudad se encuentra en dos elementos: detrás de los ojos de los personajes, escondiendo los ojos oscuros de la deidad y como una laguna de podredumbre donde descansan los cuerpos de los iniciados que se unen a la deidad transformándose: no en otros sino en ellos mismos, en su profundo yo.

La transformación o mutación no consiste en convertirse en algo o alguien diferente de quien era, sino en convertirse en su yo auténtico, en recuperar la memoria de todas sus vidas, sus cuerpos (femeninos y masculinos, adultos e infantiles). Es una materia que permite la transformación, un lodo proteico ${ }^{3}$ que mata al sujeto y lo hace renacer. De esa sustancia está hecha Ayrebarke y cuando se solidifica se crean tanto los contornos de los nuevos cuerpos, como los muros de la ciudad.

De otra parte, el espacio monstruoso se reconstruye en la multiplicidad de temporalidades pero se dirige, indefectiblemente, hacia un futuro distópico y desolador. La novela plantea una visión distópica del mundo en el año 2335, cuando hay una sola autoridad religiosa que rige el mundo desde templos satelitales, el Kuantun Inquisitorial, autoridad que controla las últimas 7 ciudades humanas (New York, Paris, Moscú, Pekín, El Cairo, Bombay y Latinia). La humanidad alcanza una cifra crítica de 111 millones de habitantes unificados por el monoteísmo obligatorio y la pureza genética que buscaba acabar con la población mutante (salvajes

3 Se hace alusión a Proteo, el personaje mítico referido en la Odisea como un dios marino capaz de cambiar de forma y que podía ver el futuro, razón por la cual es perseguido por los marinos con el fin de encontrar el rumbo en medio del caos. Su cualidad de cambiar de forma es permanente y radical, lo hace él mismo y muchos, por lo cual es casi imposible de atrapar o si quiera de asir. 
que nacen fuera de las ciudades, sin dios ni ley, desconectadas de la red satelital).

También se encuentra el Enclave-A, o la reserva forestal original donde habitan y "descubren" a los Iseieke en 1999, se convierte en el último reducto de lo humano sin eugenesia: allí las personas son de todos los colores y se transforman constantemente por la mutación mística que los marca como salvajes: ya no existen sino 7 ciudades puras, pero en el enclave que queda cerca de Latinia, no hay fronteras artificiales, se trata de un punto donde el territorio y las razas se hibridan. Así, territorio y cuerpo se hacen uno solo: espacio de la pluralidad, del mestizaje y de lo salvaje, lo incontrolado.

\section{ETAPAS PARA LA APARICIÓN DEL MONSTRUO. TERATOGÉNESIS:}

De la propuesta narrativa de Sacrilegio emerge, entonces, una nueva visión de lo monstruoso. Dicha propuesta puede describirse como una teratogénesis, es decir, como un proceso en que se construye y transforma al sujeto que se cree (en apariencia) normal y racional para reconocerse luego como un sujeto diferente. Se proponen, así, tres momentos que marcan la construcción de los personajes.

Posesión. En su texto Tratado de monstruos: ontología teratológica (2003), Héctor Santiesteban plantea que uno de los métodos para la creación de seres monstruosos está en la posesión demoniaca. "tal causa cuenta como premisa la facultad de un alma para transmigrar, aunque sea de manera momentánea, en un ser ajeno a ella" (SANTIESTEBAN, 2003, p.71). Cuando el Ofiuco quería despertar al sujeto y desatarlo lo poseía a través de tentáculos de oscuridad que eliminaban los muros de la conciencia 
y las fronteras de la memoria y de la realidad, para permitir que el dios interno de cada hombre y mujer aflorara. Así que estaban poseídos de sí mismos.

Incubación. En la novela se desarrolla un método para el cambio de los humanos a los mutantes a través del Imbunche, referencia a un hombre-semilla que se enterraba en las raíces de árboles sagrados que volvían sus raíces tentáculos y a través de la putrefacción del cuerpo lo transformaban. Pasando de una vida de unidad y vacuidad a una muerte de multiplicidad, una pesadilla de multisensorialidad, para terminar en un renacimiento como ser multitemporal y expandido.

Aparición del mutante. En el tercer momento de la teratogénesis el sujeto monstruoso es visto como un "cismático o apóstata en trance de mutación" (JÁNICAS, 2009b, p.245). Se trata de un sujeto que no está encerrado en una creencia única y es capaz de sobrevivir al encono fundamentalista, una enfermedad de la conciencia que hace metástasis en las grandes urbes. Su cuerpo responde a su maleabilidad de pensamiento cambiando de materialidad (apariencia, sexo, tamaño) constantemente. El dios multiforme serpentea en su piel y le permite ser otro.

Este proceso describe la manera en que la novela va deconstruyendo a los sujetos y los transforma, pero no unifica los resultados de este proceso de cambio, sino que unos se vuelven más humanos y otros menos. Así mismo, las percepciones de unos y otros son contradictorias pues aquellos que se recuperan y enfatizan su plural humanidad son perseguidos (se normalizan hacia adentro y se convierten en anormales para los demás), 
mientras que aquellos que se vuelven unitarios, se engañan sobre su naturaleza pues deciden desconocer la multiplicidad y optan por la monstruosa unidad, se convierten en normales para la comunidad hegemónica pero en anormales hacia sí mismo (ya que reniegan de su naturaleza verdadera).

\section{EL OFIUCO: EL DIOS DE LA HETERODOXIA Y LA MULTIPLICIDAD}

Ofiuco $^{4}$ es el nombre que recibió Asclepio luego de su metamorfosis en constelación. Según Hesíodo, Asclepio fue castigado por Zeus ante el reclamo de Hades pues el conocimiento de sanación adquirido le permitió "curar" la muerte y romper el orden natural. Al morir Asclepio fue transformado en una constelación rodeado de serpientes que remiten a la renovación constante. La novela denomina a la deidad oscura y multiforme como Ofiuco, pero, además, lo relaciona con el mito de Cronos (Saturno) y las saturnales.

Esta segunda representación mítica-simbólica hace referencia al dios heterogéneo como una bestia oscura como representación del tiempo mismo, de su fluir. Un dios de la transformación que devora a sus seguidores y se apodera de sus cuerpos desechando la inhumanidad (unidad y homogenización) para dar rienda suelta a lo profundamente humano (el intersticio entre el dolor y el placer). Esta conjunción de simbologías hace del Ofiuco un dios del umbral. Un ser monstruoso que habita en las fronteras para romperlas: frontera de la ley, de la virtud, de la lengua, de la razón, del amor, del cuerpo y finalmente de la historia y el poder.

4 Al respecto existe un solo trabajo que aborda el análisis literario de la novela y fue desarrollado por Julián David Vásquez en el año 2016 bajo el título de La serpiente como un todo, en la novela Sacrilegio de Simón Jánicas (trabajo de grado). Su orientación concuerda con este análisis por cuanto aborda el entramado simbólico que desarrolla toda la novela, pero no aborda el componente neofantástico de la misma. 


\section{CONFRONTACIÓN DE SUJETOS}

La confrontación de subjetividades se constituye en el eje fundamental de la alteridad y de la construcción de hombres monstruosos. En la novela se develan dos facciones, cada una encarnación de una creencia, así están los absolutos (hombres que optan por entenderse como únicos) y los Iseieke (seres multitemporales y multiformes o mutantes).

Alos absolutos los marca el dogma de la unidad del sujeto: unidad como metarrelato; como apariencia y simulacro. Esta facción de la humanidad desata una divinidad de la homogenización que debe ser asumida por todos a costa de tener como represaría la muerte. La guerra santa que se desata en la novela se denomina la Ordalía de los Absolutos pues se trata de juicios irracionales por tortura (como en la cacería medieval de brujas con los juicios por agua que probaban si el acusado tenía tratos con el demonio sometiéndolo a ahogamiento): linchamientos, arranques de violencia populista y finalmente, expurgación vandálica de toda heterodoxia. De ahí que la marca de los absolutos es su falta de rostro y su anonimato, se convierten en hordas enardecidas en las cuales todos se hacen uno.

En segunda instancia aparece la tribu de los Iseieke como los opositores radicales. Los enemigos de la fe unificada. Seres del umbral y sujetos de múltiples rostros. Sacrílegos que atentan contra la verdad y la luz que en texto es entendida como símbolo del conocimiento dogmático que hace estallar en cenizas a los hombres que rebosan de verdades inamovibles. La luz no ilumina y enriquece, sino que ciega y quema, todo lo destruye. Por eso el dios de la duda es el de la oscuridad. 
A partir de esta confrontación de facciones de lo humano se desarrolla el relato, pero no abandona la multiplicidad por una forma dicotómica de guerra simbólica. Prueba de ello está en la mención de los zombies. En medio del caos que se desata en el año 1999, cuando los Iseieke aparecen para transformar a la humanidad, muchos empiezan el viaje de transformación teratológico, aunque solamente en apariencia. Se trata de sujetos que aparentan cambio, pero en lo profundo son incapaces de transformarse desde adentro pues la transformación implica la muerte de su ser anterior: sus recuerdos, sus valores y finalmente su cuerpo se debería destruir para mutar. Estos seres de apariencias escuchan el mensaje de la deidad oscura pero no lo comprenden, por lo cual la verdad se convierte en ellos en una llama que devora y purga su inmovilidad carbonizándolos desde adentro. Por eso, en el relato se les describe como seres que vagan sin tiempo y que paulatinamente se desmoronan en cenizas hasta desaparecer. Incapaces de adoptar ninguna postura están condenados a la muerte definitiva, al olvido. Estos sujetos corresponden a las mayorías, a las masas indolentes y apáticas (en unos momentos) o a comunidades de empatía fingida y emoción superficial.

Sacrilegio presenta una mirada del otro que construye una crítica del hombre actual. Un hombre engañado por la información, sitiado por su creencia ciega en verdades mediáticas provenientes de los templos televisivos y de las burocracias religiosas. Un hombre que trata de homogenizarse para purgar toda discrepancia y eludir el problema de pensar diferente. Un hombre que deja de ser hombre y se hace monstruoso pues deja de ser cuando deja de pensar por sí mismo y deja de cambiar. Su 
estatismo lo condena a un infierno de soledad repitiendo ecos de lo que otros dicen, pero sin voz propia.

Así, lo que predomina es una monstruosidad en el umbral. Víctor Turner en su texto El proceso ritual. Estructura y antiestructura (1988), interpreta la liminalidad como un elemento esencial de los usos rituales, vinculado a las crisis de la vida social en las comunidades y evidencian los cambios y buscan renovarse socialmente. Turner plantea que "las personæ liminales [gentes del umbral] son necesariamente ambiguas, ya que esta condición y estas personas eluden o escapan del sistema de clasificaciones que normalmente establecen las situaciones y posiciones en el espacio cultural." (1988, p. 102). Con ello, el sentido liminal de la novela se desarrolla como una representación del cambio ideológico, del diálogo de saberes y de la interacción con los hombres diferentes que no son otros distintos, sino que somos todos.

Una declaración sobre los convulsos tiempos actuales en los que la monstruosidad humana aflora desde fachadas insospechadas: hombres que parecen libres, que parecen dialógicos, que responden aparentemente a la llamada de la modernidad y la democracia, pero son consumidos por sus demonios internos y supeditan el mundo a su deseo. La oscuridad que nos habita se muestra como una latencia, un horror soterrado esperando el momento en el ser humano se abandone a la individualidad extrema y deje morir al colectivo.

\section{REFERENCIAS}

ALAZRAKI, Jaime (2001). “¿Qué es lo neofantástico?”. In Teorías de lo fantástico. Madrid, Arco Libros.

BOIA, Lucian (1995). Entre el ángel y la bestia. Barcelona, Editorial Andrés Bello. 
JÁNICAS, Simón (2009 a). Sacrilegio. Bogotá, Diente de León. (2009 b). "Conversación en la Ópera con Simón Jánicas" y "Perfil”. In http://simonjanicas-sacrilegio.blogspot.com/ acceso en 1.Ene.2018.

LYOTARD, Jean François (1987). La condición postmoderna. Madrid: Cátedra. ROAS, David (2000). La recepción de la literatura fantástica en la España del siglo XIX. Tesis Doctoral. Barcelona, Universidad Autónoma de Barcelona.

(Ed.) (2001). Teorías de lo fantástico, Madrid: Arco/Libros.

(2013). Presentación. En: Revista de Estudios Hispánicos Pasavento, Monográfico El Monstruo Posmoderno: Nuevas estrategias de la ficción fantástica. 1(1), 7-10. In http://www.pasavento.com/numero_1.html acceso en 1.Ene. 2018.

SÁNCHEZ ÁVILA, Nini Johanna (2016). "Desdoblamiento como eje composicional en los cuentos de Germán Espinosa”. In Revista La Palabra, (29), 103-115. https:// doi.org/10.19053/01218530.n29.2016.5704 acceso en 20.Jun.2018.

SANTIESTEBAN OLIVA, Héctor (2003). Tratado de monstruos: ontología teratológica. México D.F., Plaza y Valdés.

TURNER, Victor (1988). El proceso ritual. Estructura y antiestructura. Madrid, Taurus.

VÁSQUEZ, Julián David (2016). La serpiente como un todo, en la novela Sacrilegio de Simón Jánicas. Pereira, Universidad Tecnológica De Pereira. (Monografía) In http:// repositorio.utp.edu.co/dspace/bitstream/handle/11059/7263/809933V393. pdf?sequence=1 acceso en 15.Jun.2018. 